\title{
Genetic polymorphisms in glutathione S-transferase (GST) superfamily and risk of arsenic-induced urothelial carcinoma in residents of southwestern Taiwan
}

Ling-l Hsu', Wu-Ping Chen ${ }^{1}$, Tse-Yen Yang ${ }^{1}$, Yu-Hsin Chen ${ }^{1}$, Wann-Cheng Lo' ${ }^{1}$ Yuan-Hung Wang ${ }^{2,3}$, Ya-Tang Liao ${ }^{4}$, Yu-Mei Hsueh², Hung-Yi Chiou², Meei-Maan Wu' and Chien-Jen Chen ${ }^{1 *}$

\begin{abstract}
Background: Arsenic exposure is an important public health issue worldwide. Dose-response relationship between arsenic exposure and risk of urothelial carcinoma (UC) is consistently observed. Inorganic arsenic is methylated to form the metabolites monomethylarsonic acid and dimethylarsinic acid while ingested. Variations in capacity of xenobiotic detoxification and arsenic methylation might explain individual variation in susceptibility to arsenicinduced cancers.
\end{abstract}

Methods: To estimate individual susceptibility to arsenic-induced UC, 764 DNA specimens from our long-term follow-up cohort in Southwestern Taiwan were used and the genetic polymorphisms in GSTM1, GSTT1, GSTP1 and arsenic methylation enzymes including GSTO1 and GSTO2 were genotyped.

Results: The GSTT1 null was marginally associated with increased urothelial carcinoma (UC) risk (HR, 1.91, 95\% Cl, 1.00-3.65), while the association was not observed for other GSTs. Among the subjects with cumulative arsenic exposure (CAE) $\geq 20 \mathrm{mg} / L^{*}$ year, the GSTT1 null genotype conferred a significantly increased cancer risk (RR, 3.25, 95\% Cl, 1.20-8.80). The gene-environment interaction between the GSTT1 and high arsenic exposure with respect to cancer risk was statistically significant (multiplicative model, $p=0.0151$ ) and etiologic fraction was as high as 0.86 (95\% Cl, 0.51-1.22). The genetic effects of GSTO1/GSTO2 were largely confined to high arsenic level (CAE $\geq 20$ ). Diplotype analysis showed that among subjects exposed to high levels of arsenic, the AGG/AGG variant of GSTO1 Ala140Asp, GSTO2 5'UTR (-183)A/G, and GSTO2 Asn142Asp was associated with an increased cancer risk (HRs, 4.91, $95 \% \mathrm{Cl}, 1.02-23.74)$ when compared to the all-wildtype reference, respectively.

Conclusions: The GSTs do not play a critical role in arsenic-induced urothelial carcinogenesis. The genetic effects of GSTT1 and GSTO1 on arsenic-induced urothelial carcinogenesis are largely confined to very high exposure level.

\section{Background}

Arsenic (As) exposure is an important public health issue worldwide and more than 100 million people are exposed to arsenic-contaminated water supplies that contain arsenic at a level higher than the internationally-accepted standard (10 $\mu \mathrm{g} / \mathrm{L}$ in Taiwan and USA). Chronic arsenic ingestion induces adverse health effects

\footnotetext{
* Correspondence: cjchen@ntu.edu.tw

'Genomics Research Center, Academia Sinica, No.128 Academia road, Sec 2, Nankang, Taipei 115, Taiwan

Full list of author information is available at the end of the article
}

in humans, including black-foot disease [1,2], ischemic heart disease [3,4], hypertension [5], diabetes mellitus [6], cerebrovascular and microvascular diseases $[7,8]$ and various cancers $[9,10]$. A strong association of arsenic exposure with an increased incidence of bladder cancer has been observed in the southwest (high-exposure area) and northeast (moderate-exposure area) regions of Taiwan $[11,12]$. Even with a relatively low exposure level, the association of arsenic with bladder cancer risk has also been observed in Finnish study [13]. Nonetheless, among relatively homogeneously exposed people, the

\section{Biomed Central}


disease manifestations are diverse, which suggests that there is a marked variation in susceptibility among individuals. Nutritional status, ethnicity, an early age of exposure and variations in arsenic biotransformation are all potentially responsible for differences in individual susceptibility to arsenic-induced carcinogenesis.

Most mammals, including humans, metabolize inorganic arsenic via arsenic methylation to a range of different metabolites that have different toxic potencies $[14,15]$. The classic methylation pathway involves reduction and methylation reactions via one-carbon metabolism. Pentavalent arsenicals such as arsenate As(V) or monomethylarsonic acid $[\mathrm{MMA}(\mathrm{V})]$ can be reduced to trivalent arsenite $[\mathrm{As}(\mathrm{III})]$ or monomethylarsinic acid [MMA(III)] respectively; and then methyl groups from S-adeno methionine (SAM) are used for further methylation to form the metabolites monomethylarsonic acid $[\mathrm{MMA}(\mathrm{V})]$ and dimethylarsinic acid [DMA(V)]. Variation in the production and excretion of these arsenic metabolites could explain individual variation in arsenic toxicity [16]. Recent studies have revealed that arsenic metabolic capacity may be an important risk-modifying factor for arsenic-induced health effects. Inefficient methylation of arsenic has been documented to be a significant modifier for arsenic-induced skin lesions and cancers, bladder cancer, peripheral arterial disease, hypertension and carotid atherosclerosis [17-21].

The efficiency of arsenic methylation can be influenced by genetic polymorphisms within individuals $[22,23]$. Glutathione S-transferase omega (GSTO) and arsenic (III) methyltransferase (AS3MT, or CYT19) are involved in classic arsenic methylation in a variety of animals including humans [24-26]. The GSTOs, including GSTO1 and GSTO2, can catalyze the reduction of MMA(V) to MMA(III), which is thought to be the ratelimiting step of arsenic methylation in humans [27]. The relationship between the GSTOs and arsenic metabolism has been explored to test if GSTO polymorphisms can explain variation in arsenic methylation capacity as well as variation in individual susceptibility to arsenic exposure. Most studies have not shown a significant association of this gene with extreme urinary profiles [28-30]. However, a recent study in Taiwan showed that the GSTO2 Asn142Asp (N142D) homo-variant was associated with an increased iAs\% [31]. A study of a northern Mexican population also suggested that there is an association between GSTO1 E155del and an increased percentage of inorganic arsenic, either $\mathrm{As}^{\mathrm{III}}$ or $\mathrm{As}^{\mathrm{V}}$ [32]. The association of GSTOs with As-induced health effects has also been examined in several arseniasis areas. The polymorphisms in GSTOs could be a significant modifier for arsenic-induced skin lesions and urothelial carcinoma (UC) [20,33]. For the purpose to further clarify the effect of GSTOs as well as other GST family members on arsenic-induced urinary cancers, we monitored a cohort of 764 subjects established in Southwest Taiwan in 1988 and single nucleotide polymorphisms (SNPs) genotyping was performed. The association of GSTM1, GSTT1, GSTP1, GSTO1 and GSTO2 with UC risk was examined. In addition, the joint effect of such genes with levels of arsenic exposure on cancer risk was also examined.

\section{Materials and methods Study cohort}

Putai township, located on the southwestern coast of Taiwan, is a township where blackfoot disease (BFD) is endemic and it has an overall BFD prevalence of about 2.2/1000. The residents in Putai consumed artesian well water (100-300 meters deep) for more than 50 years. Three villages, Homei, Fuhsin, and Hsinming in Putai Township have the highest BFD prevalences at 13.6, 9.6, and 10.3/1000, respectively [34]. These villages were selected as the study area. The median arsenic concentrations of the artesian well water ranged from 0.70 ppm to $0.93 \mathrm{ppm}$ in the study area. The residents stopped artesian water consumption in the 1970s when a tap water supply system was implemented. From a total of 2258 residents aged 30 or older who were registered in the study area, only 1571 who lived at least 5 days a week in the village were recruited into the study in 1988. Twenty-five subjects were excluded from the study either due to previous cancer history or incomplete personal identification information, and finally a total of 1546 subjects were recruited for the study. All the subjects were of the same Ming-Nang ethnicity. Between 1989 and 1996, about 1081 study subjects underwent six community health examinations. At this time, biological specimens were collected including urine, blood buffy coat, hair, and nails. The buffy coat samples were stored at $-80^{\circ} \mathrm{C}$ for DNA extraction at a later date. About $30 \%$ subjects refused to give the blood samples or had inadequate DNA samples. There were no differences in characteristics between the subjects with and without blood samples based on age, gender, educational level and smoking status. A total of 764 (71\%) adequate lymphocyte DNA samples were available for SNP analysis.

A standardized personal interview based on a structured questionnaire was carried out in 1988 to collect information on risk factors including sociodemographic characteristics, lifetime residential and occupational histories, drinking water supply, cigarette smoking, alcohol drinking, as well as personal and family history of disease. Detailed histories of residency and duration of drinking artesian well water were used to derive a cumulative arsenic exposure. The cumulative arsenic exposure (CAE) of each subject was defined as $\Sigma(\mathrm{Ci} \times$ 
$\mathrm{D} i)$, where $\mathrm{C} i=$ the median arsenic level $(\mathrm{mg} / \mathrm{L})$ in well water of the $i$ th village the subject had lived and $\mathrm{D} i=$ the duration (years) of drinking artesian water in the $i$ th village [35]. CAE was calculated only for those subjects for whom there was complete information on arsenic exposure due to drinking artesian well water throughout his or her lifetime. The CAE was set at " 0 " when the subjects consumed water with arsenic concentrations equal or less than $10 \mu \mathrm{g} / \mathrm{L}$.

\section{Cancer Incidence}

Individuals' unique national identification was used to link with the national cancer registry profile in Taiwan to identify the cancer status of each cohort subject. The cancer registry system was implemented in 1978 and the complete information for cancer was updated regularly for the whole Taiwan population.

\section{SNP Genotyping}

The GSTM1 and GSTT1 primer pairs (table 1) were mixed with $\beta$-globulin primer (5'-CAA CTT CAT CCA CGT TCA CC-3' and 5'-GAA GAG CCA AGG ACA GGT AC-3') in a multiplex polymerase chain reaction (PCR). PCR was performed in a total volume of $100 \mu \mathrm{L}$, containing $10 \mu \mathrm{L}$ of genomic DNA (50-100 ng), $400 \mathrm{ng}$ of each of the above primers, and 5 units of Taq polymerase (SuperTag, Protech, Taiwan). The reaction was incubated at $94^{\circ} \mathrm{C}$ for $4 \mathrm{~min}$ and subjected to 35 cycles of $94^{\circ} \mathrm{C}$ for $60 \mathrm{~s}, 55^{\circ} \mathrm{C}$ for $60 \mathrm{~s}$ and $72^{\circ} \mathrm{C}$ for $60 \mathrm{~s}$, then a final $72^{\circ} \mathrm{C}$-extension for $10 \mathrm{~min}$. Next, $10-\mu \mathrm{L}$ PCR aliquots were electrophoresed on $2 \%$ agarose gels and were stained with ethidium bromide. The internal standard fragment of $\alpha$-globulin was 268 -bp in length, whereas the amplified gene products of GSTM1 and GSTT1 were $215 \mathrm{bp}$ and $480 \mathrm{bp}$, respectively.

Determination of genotype at the GSTP1 locus by the PCR-restriction fragment length polymorphism (RFLP) method and the primers for PCR are 5'-ACC CCA GGG CTC TAT GGG AA-3' and 5'-CAG GTT GTA GTC AGC GAA G-3'. The reaction was incubated at $94^{\circ} \mathrm{C}$ for $4 \mathrm{~min}$ and subjected to 35 cycles of $94^{\circ} \mathrm{C}$ for $30 \mathrm{~s}, 60^{\circ} \mathrm{C}$ for $30 \mathrm{~s}, 72^{\circ} \mathrm{C}$ for $30 \mathrm{~s}$, and a final $72^{\circ} \mathrm{C}$ extension for $5 \mathrm{~min}$. The PCR products were digested with $5 \mathrm{U}$ of Alw261 (New England Biolabs, Beverly, MA) and the products were separated on 3\% agarose gels. The GSTP1 I105V A/G polymorphisms were classified as homozygous A/A (major allele), heterozygous for A/G, or homozygous for G/G (minor allele).

Real-time PCR: Genotyping for polymorphisms in GSTO1 A140D, K208E, E155del and GSTO2 5'UTR $(-183) \mathrm{A} / \mathrm{G}$ and N142D was performed using real-time PCR. For each of the SNPs, primer-probe sets were made using the Applied Biosystems design service (Foster City, California). Two fluorogenic minor groove binder probes were designed with different fluorescent dyes to allow single-tube genotyping. The primers for SNP genotyping are listed in table 1 . Real-time PCR was performed using $2.5 \mu \mathrm{L}$ of TaqMan $2 \times$ universal master mix (Applied Biosystems, Foster City, CA), $0.05 \mu \mathrm{L}$ of $40 \times$ primer-probe, $0.45 \mu \mathrm{L}$ of RNase- and DNase-free water, and $2 \mu \mathrm{L}$ of sample DNA, in a total volume of 5 $\mu \mathrm{L}$ per single tube reaction. DNase-free water served as the nontemplate control and DNA of known genotype was used as a positive control; both were included in each assay run. Assay conditions were $2 \mathrm{~min}$ at $50^{\circ} \mathrm{C}, 10$ min at $95^{\circ} \mathrm{C}$, and 40 cycles of PCR at $95^{\circ} \mathrm{C}$ for $15 \mathrm{~s}$ and

Table 1 The description of SNPs of arsenic-metabolized enzyme and the primers used for realtime PCR

\begin{tabular}{|c|c|c|c|c|c|}
\hline Enzyme & Base change & $\begin{array}{l}\text { Amino acid } \\
\text { change }\end{array}$ & $\begin{array}{l}\text { Variant allele } \\
\text { frequency }\end{array}$ & $\begin{array}{l}\text { Accession } \\
\text { number }\end{array}$ & Primer pairs \\
\hline GSTM1 & $\begin{array}{l}\text { Gene } \\
\text { deletion }\end{array}$ & No protein & 0.5749 & & $\begin{array}{l}\text { 5'-GAA CTC CCT GAA AAG CTA AAG C-3' \& 5'-GTT GGG CTC AAA } \\
\text { TAT ACG GTC G-3' }\end{array}$ \\
\hline GSTT1 & $\begin{array}{l}\text { Gene } \\
\text { deletion }\end{array}$ & No protein & 0.4966 & & $\begin{array}{l}\text { 5'-TTC CTT ACT GGT CCT CAC ATC TC-3' \& 5'-TCA CCG GAT CAT } \\
\text { GGC CAG CA-3' }\end{array}$ \\
\hline GSTP1 & $\begin{array}{l}\text { Exon } 5 \\
A \rightarrow G\end{array}$ & $\begin{array}{l}\text { lle105Val } \\
(1105 \mathrm{~V})\end{array}$ & 0.2256 & rs1695 & $\begin{array}{l}\text { 5'-ACC CCA GGG CTC TAT GGG AA-3' \& 5'-CAG GTT GTA GTC } \\
\text { AGC GAA G-3' }\end{array}$ \\
\hline GSTO1 & Exon $4 \mathrm{C} \rightarrow \mathrm{A}$ & $\begin{array}{l}\text { Ala140Asp } \\
\text { (A140D) }\end{array}$ & 0.1660 & rs4925 & C_11309430_30 \\
\hline GSTO1 & Exon 4 -/AGG & $\begin{array}{l}\text { Glu155del } \\
\text { (E155del) }\end{array}$ & 0.0125 & rs11509437 & $\begin{array}{l}\text { Forward: 5'-TCTAGGTGCCATCC TTG-3' } \\
\text { Reverse: 5'-TGATAGCTAGGAGAAATAA-3' }\end{array}$ \\
\hline GSTO1 & Exon $6 \mathrm{C} \rightarrow \mathrm{T}$ & $\begin{array}{l}\text { Glu208Lys } \\
\text { (K208E) }\end{array}$ & 0.0125 & rs11509438 & C__11309432_20 \\
\hline GSTO1 & Exon6 $\mathrm{A} \rightarrow \mathrm{C}$ & $\begin{array}{l}\text { Thr217Asn } \\
\text { (T217N) }\end{array}$ & 0.0000 & rs15032 & C__1174185_80 \\
\hline GSTO2 & $\begin{array}{l}\text { Exon2 } 5^{\prime} \text { UTR } \\
(-183) \\
A \rightarrow G\end{array}$ & - & 0.2032 & rs2297235 & C__3223142_1_ \\
\hline GSTO2 & Exon5 $A \rightarrow G$ & $\begin{array}{l}\text { Asn142Asp } \\
\text { (N142D) }\end{array}$ & 0.2467 & rs156697 & C__3223136_1_ \\
\hline
\end{tabular}


$60^{\circ} \mathrm{C}$ for $1 \mathrm{~min}$. Analysis was performed using the SDS, version 2.0, software. Each sample was verified visually by examining the PCR curves generated to eliminate false positives aberrant light emission.

RFLP for GSTO1 and GSTO2: The GSTO1 A140D genotype was determined by PCR-RFLP. The primers for PCR were 5'AAA GTT GTT TCT TAA ACG TGC C-3' and 5'-AAG TGA CTT GGA AAG TGG GAA-3'. The reaction was incubated at $95^{\circ} \mathrm{C}$ for $15 \mathrm{~min}$ and subjected to 35 cycles of $94^{\circ} \mathrm{C}$ for $60 \mathrm{~s}, 55^{\circ} \mathrm{C}$ for $60 \mathrm{~s}, 72^{\circ} \mathrm{C}$ for $60 \mathrm{~s}$, and a final extension for $10 \mathrm{~min}$ at $72^{\circ} \mathrm{C}$. The PCR products were digested with Cac8 I (New England Biolabs), and the products were separated on $3 \%$ agarose gels. The genotypes were determined as follows: homozygous wild type C/C: 243, 145, and $67 \mathrm{bp}$; heterozygous C/A: 388, 243, 145, and $67 \mathrm{bp}$; homozygous variants A/ A: 388 and $67 \mathrm{bp}$.

Determination of GSTO2 N142D genotype by PCRRFLP: The primers for PCR were 5'-ACT GAG AAC CGG AAC CAC AG-3' and 5'-GTA CCT CTT CCA GGT TG-3'. The reaction was incubated at $95^{\circ} \mathrm{C}$ for 10 min and subjected to 35 cycles of $95^{\circ} \mathrm{C}$ for $60 \mathrm{~s}, 62^{\circ} \mathrm{C}$ for $60 \mathrm{~s}$, and $72^{\circ} \mathrm{C}$ for $60 \mathrm{~s}$, followed by a final extension at $72^{\circ} \mathrm{C}$ for $10 \mathrm{~min}$. The PCR product was digested with MboI (New England Biolabs), and the products were separated on $3 \%$ agarose gels. The genotypes were determined as followed: homozygous wild type A/A: $280 \mathrm{bp}$; heterozygous A/G: 280, 231, and $49 \mathrm{bp}$; homozygous variants G/G: 231 and $49 \mathrm{bp}$.

For the GSTO1 A140D and GSTO2 N142D polymorphisms, all the cancer specimens and $20 \%$ of the non-cancerous specimens were repeated by RFLP-PCR. The $\kappa$ statistics were about 0.88 and the samples with discordant results were sent for DNA sequencing for genotype validation. For GSTM1 and T1, all of the cancer samples and $20 \%$ of the non-cancer samples were repeated; the samples with discordant results were repeated until two same data were shown for the genotypes. For other SNPs, 15\% of the samples were run in duplicate and all of the $\kappa$ statistics were $>0.94$. All the samples were relabeled for the experiments and the researchers were blinded to individual identities and results.

\section{Statistical analysis}

The outcome of primary interest was newly-diagnosed UC (formerly urinary transitional cell carcinoma) during the follow up. Individual follow-up person-years were calculated from the entry date into the study to the date of cancer diagnosis, death, or study end on Dec 31, 2007, whichever came first. Among 764 study subjects, the incidence of the disease outcome was calculated and the age-sex adjusted hazard ratio (HR) was estimated using Cox's proportional hazard model according to putative risk factors including age at recruitment $(<49$, 50-59, 60+years), sex, education (illiteracy, elementary school, high school or more), cigarette smoking (yes or no), alcohol drinking (yes or no) and CAE (0-9.9, 10.019.9, 20+ mg/L*year).

Tests for Hardy-Weinberg equilibrium of each genetic marker among non-cancer subjects were conducted on observed and expected genotype frequencies using Pearson's $\chi^{2}$ test with one degree of freedom. The SNPs with variant frequencies greater than $10 \%$ were included for further analysis. The incidence of UC was calculated by the genotypes of selected markers. For GSTM1 and GSTT1, genotypes were dichotomized into two categories (null and non-null genotypes). For GSTP1, GSTO1, GSTO2, genotypes were categorized into three groups (major allele homozygous, heterozygous, and homozygous variant). Cox proportional hazard regression analyses were used to estimate HRs and 95\% confidence intervals (CIs) for associations between genotypes of interest and outcome, controlling for the following putative risk factors including age (continuous), gender, educational level, and cigarette smoking. Linkage disequilibrium was analyzed by calculating D' values for GSTO1 A140D, GSTO2 5'UTR(-183)A/G, and GSTO2 N142D. D' is a coefficient of linkage disequilibrium and can be estimated as $\left(\mathrm{p}_{\mathrm{AB}} \mathrm{p}_{\mathrm{ab}}-\mathrm{p}_{\mathrm{Ab}} \mathrm{p}_{\mathrm{aB}}\right)$ where $\mathrm{p}_{\mathrm{AB}}$ is a fraction of gamete $A B$. |D'| values ranged from 1.0 when two polymorphisms were maximally associated and zero when they were randomly associated.

A stratified analysis by arsenic exposure was performed to examine whether the association of the selected markers with arsenic-induced UC depended on exposure level. To maximize the differences between two stratified groups and to avoid "zero" UC case among the subjects with relatively low exposure level and with heterozygous or homozygous variant genotype, the sensitive analysis with various CAE cutoff points was performed to monitor the optimal cutoff point for stratified analyses. We conducted gene-exposure interaction analyses using a regression model; the multivariable-adjusted HR was estimated for each group using subjects with the wild homozygote and low arsenic exposure as a reference. For the non-null and null genotypes, an interaction term was created and a $p$ value was estimated by comparing the two models with or without the interaction term. For three genotypes, two dummy variables were created as interaction terms (heterozygous*arsenic group, homozygous variant*arsenic group), and a $p$ value was estimated by comparing two models with or without the two interaction variables. The etiologic fraction for the effects of the interaction, an indication of the "departure from additivity $\left(\left[R_{11}-R_{01}-R R_{10}\right.\right.$ $\left.\left.+R_{00}\right] / R_{11}\right)$, was calculated and the $95 \% \mathrm{CI}$ was estimated using the formula described by Walker [36]. If 
the case number in the subgroup was zero, we used 0.1 instead to calculate EF and 95\% CI. All analyses were performed with SAS statistical software (version 9.1.2, SAS Institute Inc., Cary, NC, USA). The study was approved by the ethics board of the institution prior to starting the study and the informed consent was obtained from all subjects.

\section{Results}

A total of 13,317 person-years were observed during the 18 years of follow-up, with a median period: 16.4 years. By the end of 2007, a total of 41 newly-diagnosed UC had occurred during the follow-up period, yielding an incidence of 307.9 cancers per 100,000 person-years. Table 2 shows the events and follow-up person-years for UC by age at recruitment, sex, educational level, cigarette smoking, alcohol drinking and CAE. Increased UC incidence was found to be associated with older people, being male and having low education level. Education level was inversely associated with the risk of UC in a dose-response manner. Cigarette smoking and alcohol drinking was not significantly associated with cancer risk. The incidence rates of UC per 100,000 personyears was 26.4, 207.2 and 835.1 for CAE $<10.0,10.0 \leqq$ $\mathrm{CAE}<20.0$ and $\mathrm{CAE} \geq 20.0$, respectively. When compared to the $\mathrm{CAE}<10.0$ group as the reference, the HRs were 5.96 (95\% CI, 0.72-49.03) and $19.31(95 \% \mathrm{CI}$, 2.46-151.24) for the low to high exposure levels with a $p$ value 0.0003 for test for trend.

Linkage disequilibrium analysis showed that the GSTO1 Asp140 allele was strongly linked with the GSTO2 5'UTR(-183) G allele and the GSTO2 Asp142 allele (|D'|, 0.9039 and 0.9038 , respectively. $p<0.0001$ for both SNPs). The GSTO1 Glu155 deletion in exon 4 was strongly linked with the Lys 208 allele in exon 6. The incidences and age-sex-adjusted HRs for the SNPs of interest and the GSTO1 A140D-O2 A(-183) G-O2 N142D diplotype are shown in Table 3 . The GSTT1 null genotype was found to be significantly associated with an increased cancer risk (HR, 1.91, 95\% CI: 1.00-3.65, $p=0.05)$. The GSTO diplotype AGG/AGG was potentially associated with increased cancer risk, but the association was not statistically significant.

Table 2 Univariate analysis of urothelial carcinoma (UC) risk among 764 cohort subjects by age at recruitment, sex, education level, cigarette smoking, alcohol drinking and cumulative arsenic exposure

\begin{tabular}{|c|c|c|c|c|c|}
\hline Risk factors & Count(\%) & Follow-up person-years & UC & $\begin{array}{l}\text { Crude incidence } \\
\left(\text { per } 10^{5}\right)\end{array}$ & $\begin{array}{l}\text { Age- Sex adjusted } \\
\text { HR }(95 \% \mathrm{Cl})\end{array}$ \\
\hline \multicolumn{6}{|l|}{ Age at recruitment ${ }^{a}$} \\
\hline$<50$ & $390(51.1)$ & 7251 & 11 & 151.7 & ref \\
\hline $50-59$ & $270(35.3)$ & 4508 & 22 & 488.0 & $3.38(1.64-6.98)^{* *}$ \\
\hline $60+$ & 104(13.6) & 1557 & 8 & 513.8 & $3.68(1.48-9.18)^{* *}$ \\
\hline \multicolumn{6}{|l|}{ Sex ${ }^{b}$} \\
\hline Male & $336(44.0)$ & 5716 & 20 & 349.9 & ref \\
\hline Female & $428(56.0)$ & 7601 & 21 & 276.3 & $0.77(0.42-1.43)$ \\
\hline \multicolumn{6}{|l|}{ Education level } \\
\hline Illiteracy & $256(33.5)$ & 4270 & 22 & 515.2 & ref \\
\hline Elementary & $363(47.5)$ & 6386 & 18 & 281.9 & $0.64(0.32-1.25)$ \\
\hline High school and above & $145(19.0)$ & 2662 & 1 & 37.6 & $\begin{array}{l}0.11(0.01-0.83)^{*} \\
P_{\text {trend }}: 0.01\end{array}$ \\
\hline \multicolumn{6}{|l|}{ Cigarette smoking } \\
\hline No & $595(77.9)$ & 10535 & 33 & 313.2 & ref \\
\hline Yes & $169(22.1)$ & 2781 & 8 & 287.7 & $0.67(0.27-1.64)$ \\
\hline \multicolumn{6}{|l|}{ Alcohol drinking } \\
\hline No & $660(86.4)$ & 11595 & 33 & 284.6 & ref \\
\hline Yes & 104(13.6) & 1721 & 8 & 464.8 & $1.40(0.58-3.35)$ \\
\hline \multicolumn{6}{|c|}{ Cumulative arsenic exposure (mg/L*yr) } \\
\hline $0-9.9$ & 206(26.9) & 3792 & 1 & 26.4 & ref \\
\hline 10.0-19.9 & $188(24.6)$ & 3379 & 7 & 207.2 & $5.96(0.72-49.03)$ \\
\hline $20.0+$ & $183(23.9)$ & 2874 & 24 & 835.1 & $19.31(2.46-151.24))^{* *}$ \\
\hline Unknown & $187(24.6)$ & 3271 & 9 & 275.1 & $\begin{array}{l}7.11(0.86-58.83) \\
P_{\text {trend }}: 0.0003\end{array}$ \\
\hline
\end{tabular}

a: Adjusted for sex; b: Adjusted for age in a-year increment UC: urothelial carcinoma; HR: hazard ratio; $\mathrm{Cl}$ : confidence interval ${ }^{*} \mathrm{p}<0.05$; ${ }^{* *} \mathrm{p}<0.01$; ${ }^{* *} \mathrm{p}<0.0001$ 
Table 3 Univariate analysis of urothelial carcinoma risk by genotypes of GST superfamily

\begin{tabular}{|c|c|c|c|c|}
\hline & \multirow[b]{2}{*}{ No (\%) } & \multicolumn{3}{|c|}{ Urothelial carcinoma } \\
\hline & & Case no. & HR $(95 \% \mathrm{CI})$ & $P$ value \\
\hline \multicolumn{5}{|l|}{ GSTM1 } \\
\hline Non-null & $312(42.5)$ & 18 & ref & \\
\hline Null & $422(57.5)$ & 23 & $0.94(0.51-1.74)$ & 0.84 \\
\hline \multicolumn{5}{|l|}{ GSTT1 } \\
\hline Non-null & $368(50.3)$ & 14 & ref & \\
\hline Null & $363(49.7)$ & 27 & $1.91(1.00-3.65)^{*}$ & 0.05 \\
\hline \multicolumn{5}{|l|}{ GSTP1-105 } \\
\hline AA & $491(64.8)$ & 25 & ref & \\
\hline$A G$ & $192(25.3)$ & 10 & $1.07(0.51-2.23)$ & 0.86 \\
\hline GG & $75(9.9)$ & 5 & $1.71(0.64-4.56)$ & 0.29 \\
\hline $\mathrm{AG}+\mathrm{GG}$ & $267(35.2)$ & 15 & $1.21(0.64-2.31)$ & 0.56 \\
\hline \multicolumn{5}{|l|}{ GSTO1-140 } \\
\hline CC & $521(70.0)$ & 27 & ref & \\
\hline CA & $199(26.7)$ & 9 & $0.81(0.38-1.73)$ & 0.59 \\
\hline $\mathrm{AA}$ & $24(3.3)$ & 2 & $2.11(0.50-8.99)$ & 0.31 \\
\hline$C A+A A$ & $223(30.0)$ & 11 & $0.92(0.45-1.85)$ & 0.80 \\
\hline \multicolumn{5}{|l|}{ GSTO2-(-183) } \\
\hline AA & $487(64.2)$ & 26 & ref & \\
\hline$A G$ & $234(30.9)$ & 11 & $0.73(0.36-1.48)$ & 0.38 \\
\hline GG & $37(4.9)$ & 4 & $2.58(0.88-7.52)$ & 0.08 \\
\hline $\mathrm{AG}+\mathrm{GG}$ & $271(35.8)$ & 15 & $0.90(0.48-1.71)$ & 0.75 \\
\hline \multicolumn{5}{|l|}{ GSTO2-142 } \\
\hline AA & $428(56.6)$ & 20 & ref & \\
\hline$A G$ & $283(37.4)$ & 17 & $1.14(0.60-2.19)$ & 0.69 \\
\hline GG & $45(6.0)$ & 4 & $2.62(0.88-7.83)$ & 0.08 \\
\hline $\mathrm{AG}+\mathrm{GG}$ & $328(43.4)$ & 21 & $1.28(0.69-2.37)$ & 0.43 \\
\hline \multicolumn{5}{|c|}{ GSTO1(140)/O2(-183)/O2(142) } \\
\hline CAA/CAA & $397(53.8)$ & 18 & ref & \\
\hline CAA/AGG & $163(22.1)$ & 7 & $0.83(0.34-1.98)$ & 0.66 \\
\hline AGG/AGG & $20(2.7)$ & 2 & $3.08(0.70-13.54)$ & 0.13 \\
\hline Others & $158(21.4)$ & 11 & $1.55(0.73-3.28)$ & 0.25 \\
\hline
\end{tabular}

HR: adjusted for age/gender/cigarette smoking/education level HR: hazard ratio; Cl: confidence interval

${ }^{*} p<0.05 ;{ }^{* *} p<0.01$; *** $p<0.0001$

Based on the sensitive analysis with various cutoff points of arsenic exposure level, it was consistently shown that the gene effect of GSTT1 and GSTO1 A140D was largely confined to high cumulative arsenic exposure (Additional file 1). When CAE cutoff point was $20 \mathrm{mg} / \mathrm{l}^{*}$ years, the significant association of both GSTT1 and GSTO1 A140D with UC risk could be observed.

Table 4 shows the stratified analysis of the association between the SNPs and risk of UC according to CAE status with cutoff point as $20 \mathrm{mg} / \mathrm{ll}^{*}$ years. Significant association of the GSTT1 null genotype with an increased cancer risk was only observed among high exposure group with CAE $\geq 20$ (HR, 3.25, 95\% CI, 1.20-8.80, $p=$ 0.02 ). The subjects with both a high exposure level and the homozygous variant of GSTO1 Asp140 had an increased HR of 4.79 (95\% CI, 1.03-22.39, $p=0.05$ ), with incidence rates of 3508.8 per 100,000. Analysis of GSTO1/O2 showed that among the CAE $\geq 20$ subjects, the diplotype AGG/AGG had a significantly increased cancer risk compared to CAA/CAA subjects with an estimated HR of 4.91 (95\% CI, 1.02-23.74, $p=0.05$ ). No increased cancer risk for the AGG/AGG genotype was observed among the subjects with $\mathrm{CAE}<20$.

The interaction analysis of GSTT1 and arsenic exposure level on UC risk is shown in Figure 1. The subjects with GSTT1 null genotype and high arsenic exposure had a 4.1 -fold higher risk of UC (HR, 4.08, 95\% CI, $1.46-11.40, p<0.01)$ when compared to the subjects with low exposure and the GSTT1 non-null genotype. The interaction was statistically significant in the multiplicative model and the etiologic fraction was 0.86 . The interaction analysis of the GSTO1/O2 diplotype and arsenic exposure level on UC risk is shown in Figure 2. The subjects with the GSTO AGG/AGG diplotype and high arsenic exposure had a 34-fold higher cancer risk (HR, 34.43, 95\% CI, 5.03-235.74, $p<0.01$ ) when compared to the reference and the etiologic fraction was estimated to be 0.80 .

\section{Discussion}

Our study was designed to estimate gene effect together with gene and arsenic exposure interaction on the risk of urothelial carcinoma by long-term follow-up study. In the present study, the dose-response relationship between CAE and UC risk was consistent with our previous observations in southwestern and northeastern Taiwan $[11,12]$. The protective role of education level suggested that a low socioeconomic status was associated with an increased risk of As-induced UC. Cigarette smoking was not significantly associated with UC, suggesting that tobacco use plays a relatively minor role in urinary carcinogenesis in an area that has high exposure to arsenic. We propose the possibility that people who smoke in the arsenic-exposed area have a strong tendency to develop lung cancers because of a significant interaction between smoking and arsenic on lung carcinogenesis [37]. Such a tendency may have the effect of attenuating the association between smoking and UC.

Although urothelial cancer cases were limited in the study, cancer cases among 363 subjects with GSTT1 null was twice as many as the cases among 368 subjects with GSTT1 non-null and a significant association of GSTT1null with UC could be observed with the adjustment of cigarette smoking and potential confounding factors. Moreover, the genetic effect of GSTT1 on cancer risk was largely confined to high arsenic level. The interaction between GSTT1 and high exposure level was statistically significant under the multiplicative model. 
Table 4 Stratified analysis of urothelial carcinoma risk by genotypes of GSTM1, T1, P1, 01 and 02 according to cumulative arsenic exposure

\begin{tabular}{|c|c|c|c|c|c|c|c|c|}
\hline & & & $<20 \mathrm{mg} / \mathrm{L}^{*} \mathrm{yr}$ & & & & $\mathrm{E} \geqq 20 \mathrm{mg} / \mathrm{L}^{*} \mathrm{yr}$ & \\
\hline & No & Cs No. & HR $(95 \% \mathrm{Cl})$ & $\begin{array}{l}P \\
\text { value }\end{array}$ & No & Cs No. & HR $(95 \% \mathrm{Cl})$ & $P$ value \\
\hline GSTM1 & & & & & & & & \\
\hline Non-null & 165 & 4 & ref & & 70 & 10 & ref & \\
\hline Null & 211 & 4 & $0.69(0.17-2.81)$ & 0.61 & 110 & 14 & $0.90(0.40-2.03)$ & 0.79 \\
\hline GSTT1 & & & & & & & & \\
\hline Non-null & 194 & 6 & ref & & 76 & 5 & ref & \\
\hline Null & 180 & 2 & $0.27(0.05-1.37)$ & 0.11 & 104 & 19 & $3.25(1.20-8.80)^{*}$ & 0.02 \\
\hline GSTP1-105 & & & & & & & & \\
\hline $\mathrm{AA}$ & 262 & 7 & ref & & 112 & 12 & ref & \\
\hline$A G$ & 93 & 1 & $0.41(0.05-3.35)$ & 0.41 & 47 & 7 & $1.41(0.55-3.62)$ & 0.47 \\
\hline GG & 36 & 0 & 0.00 & 0.99 & 22 & 4 & $1.76(0.51-5.73)$ & 0.35 \\
\hline$A G+G G$ & 129 & 1 & $0.33(0.04-2.66)$ & 0.30 & 69 & 11 & $1.52(0.66-3.48)$ & 0.33 \\
\hline GSTO1-140 & & & & & & & & \\
\hline CC & 264 & 6 & ref & & 126 & 16 & ref & \\
\hline CA & 106 & 1 & $0.32(0.04-2.73)$ & 0.30 & 47 & 4 & $0.70(0.23-2.10)$ & 0.52 \\
\hline $\mathrm{AA}$ & 17 & 0 & 0.00 & 0.99 & 4 & 2 & $4.79(1.03-22.39)^{*}$ & 0.05 \\
\hline$C A+A A$ & 123 & 1 & $0.30(0.04-2.49)$ & 0.26 & 51 & 6 & $0.97(0.37-2.50)$ & 0.94 \\
\hline GSTO2-(-183) & & & & & & & & \\
\hline $\mathrm{AA}$ & 247 & 6 & ref & & 115 & 16 & ref & \\
\hline$A G$ & 119 & 1 & $0.23(0.03-2.02)$ & 0.19 & 61 & 6 & $0.71(0.28-1.84)$ & 0.48 \\
\hline GG & 26 & 1 & $2.04(0.23-17.88)$ & 0.52 & 6 & 2 & $2.90(0.61-13.66)$ & 0.18 \\
\hline$A G+G G$ & 145 & 2 & $0.43(0.09-2.21)$ & 0.32 & 67 & 8 & $0.87(0.37-2.05)$ & 0.74 \\
\hline GSTO2-142 & & & & & & & & \\
\hline AA & 218 & 4 & ref & & 100 & 13 & ref & \\
\hline$A G$ & 145 & 4 & $1.17(0.28-4.80)$ & 0.83 & 71 & 8 & $0.88(0.37-2.14)$ & 0.78 \\
\hline GG & 29 & 0 & 0.00 & 0.99 & 11 & 3 & 2.53(0.71-8.99) & 0.15 \\
\hline$A G+G G$ & 174 & 4 & $1.05(0.26-4.30)$ & 0.94 & 82 & 11 & $1.08(0.48-2.41)$ & 0.86 \\
\hline GSTO1(140)/O2 & & & & & & & & \\
\hline CAA/CAA & 205 & 3 & ref & & 94 & 12 & ref & \\
\hline CAA/AGG & 89 & 0 & 0.00 & 0.99 & 41 & 4 & $0.79(0.25-2.49)$ & 0.69 \\
\hline AGG/AGG & 15 & 0 & 0.00 & 1.00 & 4 & 2 & $4.91(1.02-23.74)^{*}$ & 0.05 \\
\hline Others & 77 & 4 & $3.45(0.75-15.78)$ & 0.11 & 38 & 4 & $0.85(0.27-2.65)$ & 0.78 \\
\hline
\end{tabular}

HR adjusted for age/gender/cigarette smoking/education level ${ }^{*} p<0.05 ;{ }^{* *} p<0.01 ;{ }^{* *} p<0.0001$

GST: glutathione S-transferase; CAE: cumulative arsenic exposure; HR: hazard ratio; Cl: confidence interval;

These observations suggest that GSTT1 may have a significant role in As-induced urothelial carcinogenesis, especially among high exposure level. The current result was inconsistent with the previous studies showing the GSTT1 non-null genotype was associated with an increased risk of As-induced skin lesions [38] and UC [39]. The limited sample size without sufficient power to detect true association may partly explain the discrepancies of these studies. The other possibility for these discrepancies may due to markedly difference of exposure level among these studies. We noticed the protective role of GSTT1 non-null was largely confined to the individuals with cumulative arsenic exposure higher than $20 \mathrm{mg} / \mathrm{L}^{*}$ years in the present study. On the other hand, the association of GSTT1 non-null with increased bladder cancer risk was more confined to individuals with relatively low level exposure (most study subjects have consumed contaminated water with arsenic concentration less than $0.2 \mathrm{mg} / \mathrm{L}$ for less than 30 years). These observations reveal the possibility that the effects of GSTT1 polymorphism on susceptibility to arsenicinduced urothelial carcinoma depend on arsenic exposure level. The association between GSTs and UC with regard to various arsenic exposure levels needs to be further clarified.

The roles of GSTT1 in arsenic-induced carcinogenesis remain unclear. The modulating effect of GSTs on arsenic methylation has been explored in several studies. Our previous study on the northeast coast of Taiwan has shown that the GSTT1 null genotype was associated with an 


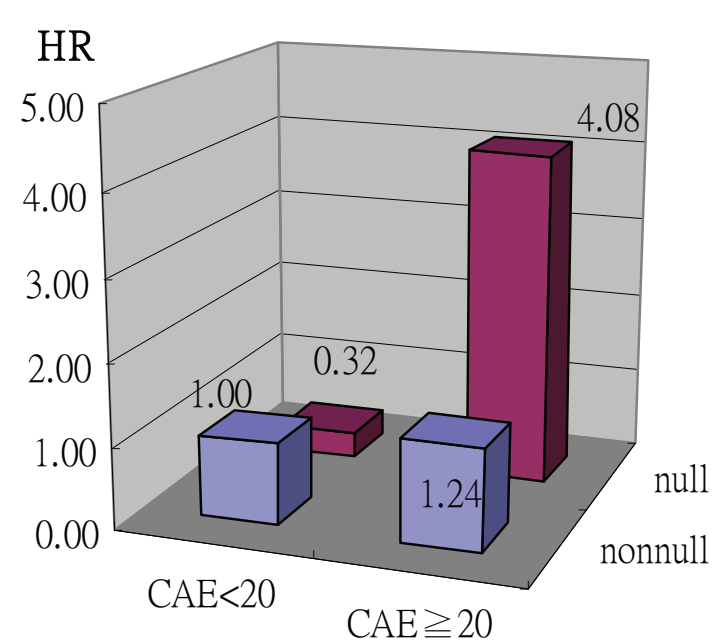

$\mathrm{P}_{\text {interaction: }} 0.0151$

EF: $0.86(0.51,1.22)$

Figure 1 Interaction analysis between arsenic exposure level and GSTT1 genotype on UC risk.

elevated percentage of dimethylarsonous acid (DMA) in urine [40]. By contrast, the study in Argentina showed that the GSTT1 null was associated with lower percentage of DMA [28]. Modification effect of the GSTT1 null on \% MMA and \%DMA was also observed in that study.
Although these studies show inconsistent results for the association between GSTs and urinary arsenic metabolite pattern, the findings indicate that the GSTT1is possibly responsible for a part of interindividual variation in arsenic metabolism. From current knowledge the GSTT1 does not

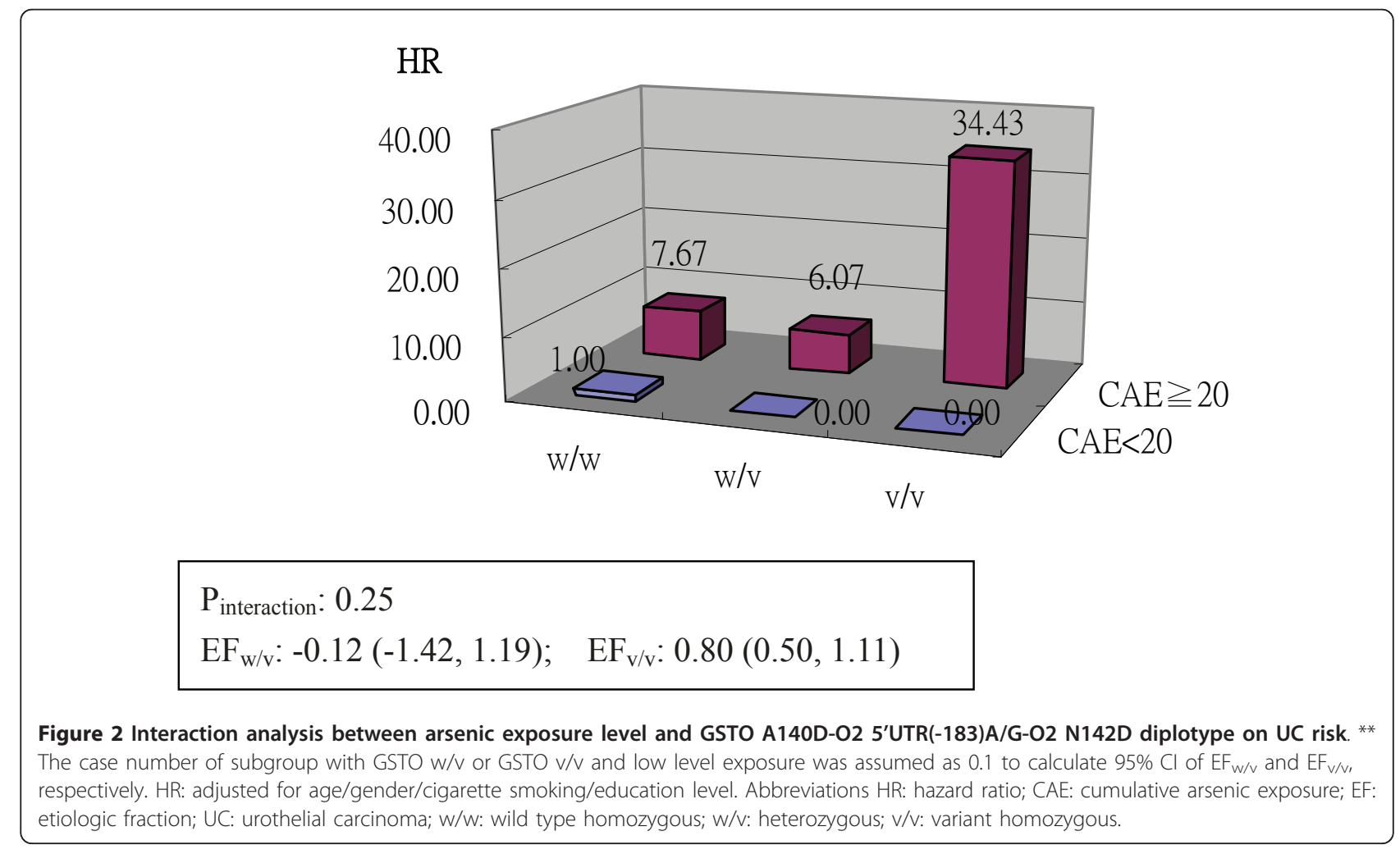


catalyze the reactions of arsenic methylation directly. Instead, GSTT1 may involve in arsenic methylation by an indirect way, for example, by depletion the glutathione (GSH) level. GSH is required for arsenic metabolism such as iAs(V) or MMA(V) reduction [36,41]. Depletion of GSH might cause decreased efficiency of arsenic methylation. The GSTT1 null may have a protective role on urothelial carcinogenesis if this enzyme can quickly deplete the GSH.

In addition to the possible roles of GSTs in arsenic biotransformation, GSTs are also phase II metabolic enzymes that are involved in detoxification of the xenobiotics by glutathione conjugation. The evidence generally supports the modulating effect of GSTM1 and GSTT1 polymorphisms on cancers closely-related to chemical exposure, including bladder cancer $[42,43]$. GSTs may prevent DNA damage from endogenously-formed oxidative stress or environmentally-exposed carcinogens [44-46]. There is considerable evidence that reactive oxygen species (ROS) are involved in the genotoxicity of arsenical compounds $[47,48]$. Our previous study in Northeastern Taiwan showed that the concentration of reactive oxidants of plasma was positively correlated with arsenic concentration in whole blood among arsenic-exposed people [49]. These phase II enzymes, perhaps GSTT1, possibly play an important role to detoxify arsenic-induced ROS. Up to now the direct reactions of GSTs toward arsenic-induced ROS have yet been reported and the relations between GSTs, arsenic-induced ROS and DNA damage need to be further addressed.

For the overall study subjects without considering arsenic exposure level, GSTO1/O2 was not associated with urothelial carcinoma, suggesting the limited role of GSTOs for urothelial carcinogenesis. However, among high As-exposed subjects with 75\% UC cases diagnosed in this subgroup (24 among a total of $32 \mathrm{UC}$ cases with known exposure levels), a significant association between GSTO polymorphism and UC was observed. In this highly-exposed group, strikingly high UC incidence was observed (3500 per 100,000) among people with GSTO1/O2 AGG/AGG diplotype. This observation suggests a possible role of GSTOs in individual susceptibility to UC especially at a high exposure level. Our result also supports the previous studies showing the modification effect of GSTOs on As-induced health effects [20,33]. For examples, GSTO2 A424G and A-183G homovariant was associated with a 1.6-fold and a 2.4fold UC risk, respectively in one hospital-based casecontrol study [33]. A study in Bangladesh also showed an joint effect of arsenic exposure with GSTOs on Asinduced skin lesions [20]. Based on these observations GSTOs might be a significant modifier for arsenicinduced carcinogenesis. However, the magnitude of the association between GSTOs polymorphisms and As- induced cancers across different exposure levels has not been well-evaluated. Further studies with larger sample size, precise exposure assessment and large variation of exposure level are needed to draw these issues.

Both GSTO1 and GSTO2 are involved in arsenic methylation catalyzing the reduction of pentavalent arsenicals to trivalent arsenicals. Different GSTO polymorphisms may be of different capacity of arsenic metabolism, which may explain for variation susceptibility to arsenic. Inefficient methylation of arsenic has been reported to be associated with arsenic-induced skin lesions, skin cancers, bladder cancers and cardiovascular diseases [17-21]. Our previous study indicated that GSTO2 N142D GG genotype was associated with a higher percentage of iAs [31]. Two studies displayed that GSTO1 E155del was associated with markedlychanged percentage of iAs when compared to the wild homotype [32,50]. These studies suggest the effects of GSTOs polymorphisms on percentage of iAs. However, the association of GSTO1 with urinary arsenic metabolite pattern remains inconclusive because several studies did not show a significant association [28-30]. The inconsistent results among these studies might be due to very little concern for potential confounding factors such as ethnicity, nutritional status, As exposure level and other environmental factors. Better control of these confounding factors in further studies helps evaluation of real effect of GSTOs on arsenic methylation. In addition to $\mathrm{MMA}(\mathrm{V}) / \mathrm{DMA}(\mathrm{V})$ reductase activities, GSTOs also exhibits high thioltransferase activity as well as dehydroascorbate reductase activity and thus the enzymes could participate in intracellular thiol homeostatic reactions and antioxidant ascorbate recycling, respectively. Such enzyme activities reveal another possibility whereby changes in thioltransferase activity as well as ascorbate reductase activity may explain individual susceptibility to arsenic-induced health effects.

The present study had several limitations. Firstly, the small sample size with a limited number of cancer cases is a major limitation of this study. Based on such limited case numbers, a significant association of genetic markers with cancer risk is hard to reach after a Bonferroni correction for multiple comparisons. For this concern, we performed permutation tests to obtain the empirical $p$-value to overcome the size limitation and multiple testing issues (data not shown). Permutation is a nonparametric test and the empirical p-value can be obtained by calculating all possible test statistic under random rearrangements of the disease status on the study subjects [51]. The permutation tests performed for this study revealed the same results with that obtained by traditional statistical analysis, giving additional support for such gene-disease association. A second limitation is that about one-fourth of individual's CAE is 
missing, which decreases the power for the estimate of gene-environment interaction. Finally, the estimates of exposure status from questionnaires are subject to recall bias. However, the recall bias is considered to be nondifferential between the cases and non-cases and thus the HRs should be underestimated. Notwithstanding these limitations, it is clear that this study was able to estimate the genetic effects of GSTT1 and GSTOs on the risk of $U C$, and, furthermore, the interactions between polymorphisms of such genes and high-level arsenic exposure can still be identified.

\section{Conclusion}

We estimated the gene effects of members of GST superfamily on arsenic-induced urothelial carcinoma by longterm follow-up study in southwestern Taiwan. The results reveal the fact that the GSTs do not play a critical role in arsenic-induced urothelial carcinogenesis. However, the present data provide evidence that the effects of GSTT1 and GSTOs on arsenic-induced UC are possibly confined to high exposure level, where the subjects had UC risk almost twenty-fold higher than that of low exposure level. These observations are helpful for the identification of high risk group of urothelial carcinoma among arsenic-exposed people. In the future, the studies with a larger sample size, longer follow-up periods, markedly variation of exposure level as well as better control of confounding factors are needed to estimate single gene, gene-gene and gene-environmental interaction on the risk of adverse arsenic-induced health effects.

\section{Additional material}

Additional file 1: Sensitive analysis of the association of GSTs with the risk of urothelial carcinoma according to various cutoff points of arsenic exposure level.

\section{List of abbreviations}

As: arsenic; GST: glutathione S-transferase; GSTO: Glutathione S-transferase omega; UC: urothelial carcinoma; As(V): pentavalent arsenate; As(III): trivalent arsenite; MMA(V): monomethylarsonic acid; MMA(III): monomethylarsinic acid; DNA(V): dimethylarsinic acid; SAM: S-adeno methionine; AS3MT: arsenic (III) methyltransferase; SNPs: single nucleotide polymorphisms; BFD: blackfoot disease; CAE: cumulative arsenic exposure; PCR: polymerase chain reaction; RFLP: restriction fragment length polymorphism; HR: hazard ratio; $\mathrm{Cl}$ : confidence interval; EF: etiologic fraction; ROS: reactive oxidative stress; w/W: wild type homozygous; w/v: heterozygous; v/v: variant homozygous

\section{Acknowledgements and Funding}

We thank Genetic Epidemiology Core Laboratory, Division of Genomic Medicine, Research Center for Medical Excellence, National Taiwan University, for providing us technical support for Permutation tests. This study was supported by National Science Council, Executive Yuan, Republic of China (NSC95-2314-B-001-006, NSC96-2314-B-001-003)

\section{Author details}

${ }^{1}$ Genomics Research Center, Academia Sinica, No.128 Academia road, Sec 2 Nankang, Taipei 115, Taiwan. ${ }^{2}$ School of Public Health, Taipei Medical
University, 250 Wu-Xin Street, Taipei 110 Taiwan. ${ }^{3}$ Department of Urology, Taipei Medical University Hospital, 250 Wu-Xin Street, Taipei 110. ${ }^{4}$ Division of Environmental Health and Occupational Medicine, National Health Research Institutes, Taiwan.

\section{Authors' contributions}

CJC and LIH had full access to all of the data in the study and take responsibility for the integrity of the data and the accuracy of the data analysis. Study concept and design: CJC, LIH. Acquisition of data: CJC, LIH, WPC, YHC, WCL.

Analysis and interpretation of data: CJC, LIH. Drafting of the manuscript: $\mathrm{LIH}$. Critical revision of the manuscript for important intellectual content: CJC. Experiment operating: WPC, YHC, WCL. Statistical analysis: LIH, CJC. Obtained funding: CJC. Administrative, technical, or material support: CJ Ch, LIH, TYY, YHW, YMH, HYC, MMW. Study supervision: CJC.

All authors read and approved the final manuscript.

\section{Competing interests}

We declare that we have no conflict of interest and none of the funding organization played a role in the design and conducted of this study; collection, management, analysis, and interpretation of the data; or preparation, review, and approval of the manuscript.

Received: 3 March 2011 Accepted: 29 July 2011 Published: 29 July 2011

\section{References}

1. Chen CJ: Blackfoot disease. Lancet 1990, 336:442.

2. Tseng WP: Effects and dose-response relationships of skin cancer and blackfoot disease with arsenic. Environ Health Perspect 1977, 19:109-119.

3. Chen CJ, Chiou HY, Chiang MH, Lin LJ, Tai TY: Dose-response relationship between ischemic heart disease mortality and long-term arsenic exposure. Arterioscler Thromb Vasc Biol 1996, 16:504-510.

4. Tseng CH, Chong CK, Tseng CP, Hsueh YM, Chiou HY, Tseng CC, Chen CJ: Long-term arsenic exposure and ischemic heart disease in arseniasishyperendemic villages in Taiwan. Toxicol Lett 2003, 137:15-21.

5. Chen CJ, Hsueh YM, Lai MS, Shyu MP, Chen SY, Wu MM, Kuo TL, Tai TY: Increased prevalence of hypertension and long-term arsenic exposure. Hypertension 1995, 25:53-60.

6. Lai MS, Hsueh YM, Chen CJ, Shyu MP, Chen SY, Kuo TL, Wu MM, Tai TY: Ingested inorganic arsenic and prevalence of diabetes mellitus. Am J Epidemiol 1994, 139:484-492.

7. Chiou HY, Huang WI, Su CL, Chang SF, Hsu YH, Chen CJ: Dose-response relationship between prevalence of cerebrovascular disease and ingested inorganic arsenic. Stroke 1997, 28:1717-1723.

8. Tseng CH, Chong CK, Chen CJ, Tai TY: Dose-response relationship between peripheral vascular disease and ingested inorganic arsenic among residents in blackfoot disease endemic villages in Taiwan. Atherosclerosis 1996, 120:125-133.

9. Chen CJ, Kuo TL, Wu MM: Arsenic and cancers. Lancet 1988, 1:414-415.

10. Wu MM, Kuo TL, Hwang YH, Chen CJ: Dose-response relation between arsenic concentration in well water and mortality from cancers and vascular diseases. Am J Epidemiol 1989, 130:1123-1132.

11. Chiou HY, Chiou ST, Hsu YH, Chou YL, Tseng CH, Wei ML, Chen CJ: Incidence of transitional cell carcinoma and arsenic in drinking water: a follow-up study of 8,102 residents in an arseniasis-endemic area in northeastern Taiwan. Am J Epidemiol 2001, 153:411-418.

12. Chiou HY, Hsueh YM, Liaw KF, Horng SF, Chiang MH, Pu YS, Lin JS, Huang $\mathrm{CH}$, Chen $\mathrm{CJ}$ : Incidence of internal cancers and ingested inorganic arsenic: a seven-year follow-up study in Taiwan. Cancer Res 1995, 55:1296-1300.

13. Kurttio P, Pukkala E, Kahelin H, Auvinen A, Pekkanen J: Arsenic concentrations in well water and risk of bladder and kidney cancer in Finland. Environ Health Perspect 1999, 107:705-710.

14. Styblo M, Del Razo LM, Vega L, Germolec DR, LeCluyse EL, Hamilton GA Reed W, Wang C, Cullen WR, Thomas DJ: Comparative toxicity of trivalent and pentavalent inorganic and methylated arsenicals in rat and human cells. Arch Toxicol 2000, 74:289-299.

15. Styblo M, Drobna Z, Jaspers I, Lin S, Thomas DJ: The role of biomethylation in toxicity and carcinogenicity of arsenic: a research update. Environ Health Perspect 2002, 110(Suppl 5):767-771. 
16. Vahter M: Genetic polymorphism in the biotransformation of inorganic arsenic and its role in toxicity. Toxicol Lett 2000, 112-113:209-217.

17. Tseng $\mathrm{CH}$, Huang $\mathrm{YK}$, Huang $\mathrm{YL}$, Chung $\mathrm{CJ}$, Yang MH, Chen CJ, Hsueh YM: Arsenic exposure, urinary arsenic speciation, and peripheral vascular disease in blackfoot disease-hyperendemic villages in Taiwan. Toxicol Appl Pharmacol 2005, 206:299-308.

18. Chung CJ, Huang CJ, Pu YS, Su CT, Huang YK, Chen YT, Hsueh YM: Urinary 8-hydroxydeoxyguanosine and urothelial carcinoma risk in low arsenic exposure area. Toxicol Appl Pharmacol 2008, 226:14-21.

19. Huang YL, Hsueh YM, Huang YK, Yip PK, Yang MH, Chen CJ: Urinary arsenic methylation capability and carotid atherosclerosis risk in subjects living in arsenicosis-hyperendemic areas in southwestern Taiwan. Sci Total Environ 2009, 407:2608-2614

20. Ahsan H, Chen Y, Kibriya MG, Slavkovich V, Parvez F, Jasmine F, Gamble MV, Graziano JH: Arsenic metabolism, genetic susceptibility, and risk of premalignant skin lesions in Bangladesh. Cancer Epidemiol Biomarkers Prev 2007, 16:1270-1278.

21. McCarty KM, Chen YC, Quamruzzaman Q, Rahman M, Mahiuddin G Hsueh YM, Su L, Smith T, Ryan L, Christiani DC: Arsenic methylation, GSTT1, GSTM1, GSTP1 polymorphisms, and skin lesions. Environ Health Perspect 2007, 115:341-345.

22. Hernandez A, Marcos R: Genetic variations associated with interindividual sensitivity in the response to arsenic exposure. Pharmacogenomics 2008, 9:1113-1132.

23. Tseng $\mathrm{CH}$ : A review on environmental factors regulating arsenic methylation in humans. Toxicol Appl Pharmacol 2009, 235:338-350.

24. Board PG, Coggan M, Chelvanayagam G, Easteal S, Jermiin LS, Schulte GK, Danley DE, Hoth LR, Griffor MC, Kamath AV, et al: Identification, characterization, and crystal structure of the Omega class glutathione transferases. J Biol Chem 2000, 275:24798-24806

25. Lin S, Shi Q, Nix FB, Styblo M, Beck MA, Herbin-Davis KM, Hall LL, Simeonsson JB, Thomas DJ: A novel S-adenosyl-L-methionine:arsenic(III) methyltransferase from rat liver cytosol. J Biol Chem 2002, 277:10795-10803.

26. Zakharyan RA, Sampayo-Reyes A, Healy SM, Tsaprailis G, Board PG Liebler DC, Aposhian HV: Human monomethylarsonic acid (MMA(V)) reductase is a member of the glutathione-S-transferase superfamily. Chem Res Toxicol 2001, 14:1051-1057.

27. Schmuck EM, Board PG, Whitbread AK, Tetlow N, Cavanaugh JA, Blackburn AC, Masoumi A: Characterization of the monomethylarsonate reductase and dehydroascorbate reductase activities of Omega class glutathione transferase variants: implications for arsenic metabolism and the age-at-onset of Alzheimer's and Parkinson's diseases. Pharmacogenet Genomics 2005, 15:493-501

28. Schlawicke Engstrom K, Broberg K, Concha G, Nermell B, Warholm M, Vahter M: Genetic polymorphisms influencing arsenic metabolism: evidence from Argentina. Environ Health Perspect 2007, 115:599-605.

29. Paiva L, Marcos R, Creus A, Coggan M, Oakley AJ, Board PG: Polymorphism of glutathione transferase Omega 1 in a population exposed to a high environmental arsenic burden. Pharmacogenet Genomics 2008, 18:1-10.

30. Lindberg AL, Kumar R, Goessler W, Thirumaran R, Gurzau E, Koppova K, Rudnai P, Leonardi G, Fletcher T, Vahter M: Metabolism of low-dose inorganic arsenic in a central European population: influence of sex and genetic polymorphisms. Environ Health Perspect 2007, 115:1081-1086.

31. Chung CJ, Hsueh YM, Bai CH, Huang YK, Huang YL, Yang MH, Chen CJ: Polymorphisms in arsenic metabolism genes, urinary arsenic methylation profile and cancer. Cancer Causes Control 2009, 20:1653-1661.

32. Marnell LL, Garcia-Vargas GG, Chowdhury UK, Zakharyan RA, Walsh B, Avram MD, Kopplin MJ, Cebrian ME, Silbergeld EK, Aposhian HV: Polymorphisms in the human monomethylarsonic acid (MMA V) reductase/hGSTO1 gene and changes in urinary arsenic profiles. Chem Res Toxicol 2003, 16:1507-1513.

33. Wang YH, Yeh SD, Shen KH, Shen CH, Juang GD, Hsu LI, Chiou HY, Chen CJ: A significantly joint effect between arsenic and occupational exposures and risk genotypes/diplotypes of CYP2E1, GSTO1 and GSTO2 on risk of urothelial carcinoma. Toxicol Appl Pharmacol 2009, 241:111-118.

34. Wu HY CK, Tseng WP, Hsu CL: Epidemiologic studies on blackfoot disease. I. Prevalence and incidence of the disease by age, sex, year occupation and geographical distribution. In Book Epidemiologic studies on blackfoot disease. I. Prevalence and incidence of the disease by age, sex, year occupation and geographical distribution. Volume 7. City: National Taiwan University; 1961:33-50

35. Seidegard J, Ekstrom G: The role of human glutathione transferases and epoxide hydrolases in the metabolism of xenobiotics. Environ Health Perspect 1997, 105(Suppl 4):791-799.

36. Brambila EM, Achanzar WE, Qu W, Webber MM, Waalkes MP: Chronic arsenic-exposed human prostate epithelial cells exhibit stable arsenic tolerance: mechanistic implications of altered cellular glutathione and glutathione S-transferase. Toxicol Appl Pharmacol 2002, 183:99-107.

37. Chen CL, Hsu LI, Chiou HY, Hsueh YM, Chen SY, Wu MM, Chen CJ: Ingested arsenic, cigarette smoking, and lung cancer risk: a follow-up study in arseniasis-endemic areas in Taiwan. Jama 2004, 292:2984-2990.

38. McCarty KM, Ryan L, Houseman EA, Williams PL, Miller DP, Quamruzzaman Q, Rahman M, Mahiuddin G, Smith T, Gonzalez E, et al: A case-control study of GST polymorphisms and arsenic related skin lesions. Environ Health 2007, 6:5.

39. Hsu LI, Chiu AW, Huan SK, Chen CL, Wang YH, Hsieh Fl, Chou WL, Wang LH, Chen CJ: SNPs of GSTM1, T1, P1, epoxide hydrolase and DNA repair enzyme XRCC1 and risk of urinary transitional cell carcinoma in southwestern Taiwan. Toxicol Appl Pharmacol 2008, 228:144-155.

40. Chiou HY, Hsueh YM, Hsieh LL, Hsu LI, Hsu YH, Hsieh Fl, Wei ML, Chen HC, Yang HT, Leu LC, et al: Arsenic methylation capacity, body retention, and null genotypes of glutathione S-transferase M1 and T1 among current arsenic-exposed residents in Taiwan. Mutat Res 1997, 386:197-207.

41. Yeh JY, Cheng LC, Ou BR, Whanger DP, Chang LW: Differential influences of various arsenic compounds on glutathione redox status and antioxidative enzymes in porcine endothelial cells. Cell Mol Life Sci 2002 59:1972-1982.

42. Brockmoller J, Cascorbi I, Kerb R, Roots I: Combined analysis of inherited polymorphisms in arylamine $\mathrm{N}$-acetyltransferase 2, glutathione $\mathrm{S}$ transferases $\mathrm{M} 1$ and $\mathrm{T} 1$, microsomal epoxide hydrolase, and cytochrome P450 enzymes as modulators of bladder cancer risk. Cancer Res 1996, 56:3915-3925.

43. Hung RJ, Boffetta P, Brennan P, Malaveille C, Hautefeuille A, Donato F, Gelatti U, Spaliviero M, Placidi D, Carta A, et al: GST, NAT, SULT1A1, CYP1B1 genetic polymorphisms, interactions with environmental exposures and bladder cancer risk in a high-risk population. Int I Cancer 2004, 110:598-604.

44. Hayes JD, McLellan LI: Glutathione and glutathione-dependent enzymes represent a co-ordinately regulated defence against oxidative stress. Free Radic Res 1999, 31:273-300

45. Spiteri MA, Bianco A, Strange RC, Fryer AA: Polymorphisms at the glutathione S-transferase, GSTP1 locus: a novel mechanism for susceptibility and development of atopic airway inflammation. Allergy 2000, 55(Suppl 61):15-20

46. Di Pietro G, Magno LA, Rios-Santos F: Glutathione S-transferases: an overview in cancer research. Expert Opin Drug Metab Toxicol 2010, 6:153-170

47. Liu SX, Athar M, Lippai I, Waldren C, Hei TK: Induction of oxyradicals by arsenic: implication for mechanism of genotoxicity. Proceedings of the National Academy of Sciences of the United States of America 2001, 98:1643-1648

48. De Vizcaya-Ruiz A, Barbier O, Ruiz-Ramos R, Cebrian ME: Biomarkers of oxidative stress and damage in human populations exposed to arsenic. Mutat Res 2009, 674:85-92.

49. Wu MM, Chiou HY, Wang TW, Hsueh YM, Wang IH, Chen CJ, Lee TC: Association of blood arsenic levels with increased reactive oxidants and decreased antioxidant capacity in a human population of northeastern Taiwan. Environ Health Perspect 2001, 109:1011-1017.

50. Agusa T, Iwata H, Fujihara J, Kunito T, Takeshita H, Minh TB, Trang PT, Viet PH, Tanabe S: Genetic polymorphisms in glutathione S-transferase (GST) superfamily and arsenic metabolism in residents of the Red River Delta, Vietnam. Toxicol Appl Pharmacol 2010, 242:352-362.

51. Potter DM: A permutation test for inference in logistic regression with small- and moderate-sized data sets. Stat Med 2005, 24:693-708.

doi:10.1186/1423-0127-18-51

Cite this article as: Hsu et al: Genetic polymorphisms in glutathione S-transferase (GST) superfamily and risk of arsenic-induced urothelial carcinoma in residents of southwestern Taiwan. Journal of Biomedical Science 2011 18:51. 